\title{
RASIO NATRIUM KARBONAT DALAM EKSTRAKSI BERPENGARUH PADA MUTU NATRIUM ALGINAT SARGASSUM MUTICUM
}

\author{
THE EFFECT OF SODIUM CARBONATE EXTRACTION RATIO \\ ON THE QUALITY OF ALGINATE FROM SARGASSUM MUTICUM
}

\author{
${ }^{1}$ Sovia Indah Nurkhanifah dan Amir Husni ${ }^{*}$ \\ Departemen Perikanan Fakultas Pertanian Universitas Gadjah Mada
}

Submitted: 20-12-2018; Revised: 01-10-2019; Accepted: 01-10-2019

\begin{abstract}
Brown seaweed is one of Indonesia's biological resources which has good potential as source for alginate which can be used for the food and non-food industries. Alginate was most widely used in the textile sector around $50 \%$, food industry $30 \%$, paper industry $6 \%$, welding rods $5 \%$, pharmacy $5 \%$ and other $4 \%$. The process of taking alginate from brown seaweed can be done by extraction. Several studies have been carried out in an effort to improve the yield of alginate extraction. The objective of this study was to determine the effect of the ratio of $\mathrm{Na}_{2} \mathrm{CO}_{3}$ and obtain the best ratio of $\mathrm{Na}_{2} \mathrm{CO}_{3}$ for producing sodium alginate from Sargassum muticum. The ratio of $\mathrm{Na}_{2} \mathrm{CO}^{3}$ used was 1:10, 1:20, 1:30, 1:40, 1:50 (w/v) and observations of alginate quality included yield (\%), viscosity (cps), $\mathrm{pH}$, water content (\%), whiteness degree (\%), ash content (\%) and functional groups. The results showed that the higher the ratio of $\mathrm{Na}_{2} \mathrm{CO}_{3}$ produced the lower viscosity and showed significantly different values but yield, $\mathrm{pH}$, water content, whiteness degree, and ash content were not significantly different. The functional groups at the ratio 1:20, 1:30, and 1:40 (w/v) showed the alginate that were in accordance with the standard. The best ratio of $\mathrm{Na}_{2} \mathrm{CO}_{3}$ from this study was 1:20 (w/v) because it had a medium viscosity, besides that, the yield, $p H$, water content, whiteness degree, and ash content also accordance to the quality of alginate standard.
\end{abstract}

Keywords: $\mathrm{Na}_{2} \mathrm{CO}_{3}$ Ratio; Extraction; Quality; Sodium Alginat; Sargassum muticum.

\begin{abstract}
ABSTRAK
Rumput laut cokelat merupakan salah satu sumber daya hayati Indonesia yang mempunyai potensi cukup baik untuk menghasilkan alginat yang dapat digunakan untuk industri pangan maupun non pangan. Alginat paling banyak digunakan dalam bidang tekstil sekitar $50 \%$, industri pangan $30 \%$, industri kertas $6 \%$, welding rods $5 \%$, farmasi $5 \%$ dan lainnya $4 \%$. Proses pengambilan alginat dari rumput laut cokelat dapat dilakukan melalui ekstraksi. Beberapa penelitian telah dilakukan dalam upaya untuk meningkatkan hasil ekstraksi alginat. Tujuan penelitian ini yaitu untuk mengetahui pengaruh rasio $\mathrm{Na}_{2} \mathrm{CO}_{3}$ dan memperoleh rasio $\mathrm{Na}_{2} \mathrm{CO}_{3}$ terbaik pada mutu natrium alginat Sargassum muticum. Rasio $\mathrm{Na}_{2} \mathrm{CO}_{3}$ yang dipakai adalah 1:10, 1:20, 1:30, 1:40, 1:50 (w/v) dan dilakukan pengamatan mutu meliputi rendemen (\%), viskositas (cps), $\mathrm{pH}$, kadar air (\%), derajat putih (\%), kadar abu (\%) dan gugus fungsi. Data yang diperoleh menunjukkan bahwa semakin tinggi rasio $\mathrm{Na}_{2} \mathrm{CO}_{3}$ maka viskositas semakin rendah dan berbeda nyata namun rendemen, $\mathrm{pH}$, kadar air, derajat putih, dan kadar abu tidak
\end{abstract}

*Corresponding author: a-husni@ugm.ac.id

Copyright (C) 2020 THE AUTHOR(S).This article is distributed under a Creative Commons Attribution-Share Alike 4.0 International license. Jurnal Teknosains is published by the Graduate School of Universitas Gadjah Mada. 
berbeda nyata. Gugus fungsi pada rasio 1:20, 1:30, dan 1:40 (w/v) menunjukkan hasil alginat sesuai dengan standar. Rasio $\mathrm{Na}_{2} \mathrm{CO}_{3}$ terbaik hasil penelitian ini adalah 1:20 (w/v) karena memiliki viskositas medium, selain itu, rendemen, $\mathrm{pH}$, kadar air, derajat putih, kadar abu juga sudah memenuhi standar mutu alginat.

Kata Kunci: Rasio $\mathrm{Na}_{2} \mathrm{CO}_{3 ;}$ Ekstraksi; Mutu; Natrium Alginat; Sargassum muticum

\section{PENGANTAR}

Indonesia sebagai negara kepulauan berpotensi besar untuk pengembangan komoditi rumput laut. Produksi rumput laut tahun 2009 hingga 2013 mengalami peningkatan dari 2.963.556 ton menjadi 9.298.474 ton (Direktorat Jenderal Perikanan Budidaya, 2013). Rumput laut di perairan Indonesia ada sekitar 782 jenis dan 134 jenis diantaranya adalah tergolong rumput laut cokelat (Sukma dkk., 2017) termasuk di dalamnya adalah Sargassum sp. yang dikenal sebagai penghasil alginat (Mushollaeni dan Rusdiana, 2011).

Alginat merupakan polimer poliglukoronat, tersusun atas asam D-mannuronat dan asam L-guluronat (Winarno, 1990). Sifat alginat dipengaruhi oleh tingkat polimerisasi dan perbandingan komposisi guluronat dan mannuronat didalam molekul. Asam alginat tidak larut air dan mengendap pada $\mathrm{pH}<3,5$. Alginat paling stabil pada $\mathrm{pH}$ antara 4-10, akan tetapi pada $\mathrm{pH}$ yang lebih tinggi viskositasnya justru sangat rendah (Rasyid, 2003) dan labil pada $\mathrm{pH}$ dibawah 4,5 dan diatas 11 (Yulianto, 2007). Alginat juga merupakan kelompok pikokoloid yang banyak digunakan untuk pengatur keseimbangan, bahan pengental, pembentuk lapisan tipis terhadap minyak dan pengemulsi (Rasyid, 2010). Alginat paling banyak digunakan pada bidang industri tekstil yaitu sekitar $50 \%$, kemudian industri pangan $30 \%$, industri kertas $6 \%$, welding rods $5 \%$, farmasi $5 \%$ dan lainnya $4 \%$ (McHugh, 1987).

Alginat dari rumput laut cokelat dapat diperoleh melalui ekstraksi (Jayanudin dkk., 2014). Sa'adah (2017) melakukan ekstraksi pada Sargassum muticum menggunakan jalur asam dan kalsium. Hasil yang diperoleh yaitu jalur asam lebih baik dibandingkan dengan jalur kalsium, namun demikian rendemen dan viskositas dalam ekstraksi tergolong rendah. Menurut Aristiya dkk. (2017), rendemen dan viskositas adalah dua sifat sangat penting dalam alginat. Rasio pelarut merupakan salah satu faktor yang mempengaruhi hasil ekstraksi (Jayanudin dkk., 2014), semakin banyak pelarut yang dipakai akan semakin banyak rantai panjang alginat yang terpotong (McHugh, 1987). Rasio pelarut adalah perbandingan antara berat rumput laut yang digunakan dalam ekstrasi berbanding dengan pelarut ekstraksi. Pelarut yang digunakan dalam ekstraksi alginat adalah $\mathrm{Na}_{2} \mathrm{CO}_{3}$ (Jayanudin dkk., 2014). Rasio $\mathrm{Na}_{2} \mathrm{CO}_{3}$ yang digunakan dalam ekstraksi alginate berpengaruh pada rendemen dan viskositas alginate yang dihasilkan (Zailanie dkk., 2001; Wibowo dkk., 2013; Jayanudin dkk.,2014). Oleh karena itu penelitian ini bertujuan untuk mengetahui pengaruh variasi rasio $\mathrm{Na}_{2} \mathrm{CO}_{3}$ dalam ekstraksi S. muticum terhadap mutu natrium alginat yang dihasilkan.

\section{Metode \\ Alat dan Bahan}

Peralatan pada penelitian ini antara lain kain blacu, waterbath shaker (Sibata, Tokyo:WS-240), pengaduk/spatula, gelas beker (Herma), gelas ukur $100 \mathrm{ml}$ (Herma), Erlenmeyer (Iwaki Pyrex), saringan (Test-sieve I.S.O,Tokyo), baskom plastik, pipet ukur (Iwaki Pyrex), kempot/pipet filler, blender (Philips), corong (Herma), pH meter ATC, kertas pH (Merck KgaA, Germany), chromameter (Konika Minolta: CR300), aluminium foil (Total Wrap), hot plate stirer (Arec), freezer (Modena dan LG), Moisture Analyzer (OHOUS:MB35), Viscometer Brookfield dan FTIR (IR Prestige-21). Bahan pokok yang digunakan dalam penelitian adalah S.muticum dari Kepulauan Alor, $\mathrm{KOH}$ teknis 0,1 \% (PT Brataco), akuadesh, $\mathrm{HCl} 1 \%$ dan 10\% (Mallinckrodt Chemicals, USA), $\mathrm{Na}_{2} \mathrm{CO}_{3} 2 \%$ dan $10 \%$ (PT Brataco), isopropil alkohol teknis (PT Brataco), $\mathrm{NaOCl} 10$ \% (PT. Brataco). 


\section{Persiapan Sampel}

Sampel rumput laut cokelat dicuci bersih dengan menggunakan air mengalir, kemudian diambil beberapa talus yang utuh lengkap dengan holdfast untuk direndam dengan alkohol 70\% untuk diidentifikasi. Sampel yang tidak diidentifikasi ditimbang dan dicuci sampai bersih, kemudian direndam dalam $\mathrm{KOH} 0,1 \%$ selama satu jam selanjutnya dicuci lagi supaya residu alkali dapat hilang. Rumput laut kemudian dijemur hingga kadar air kurang dari $15 \%$. Setelah rumput laut kering, dilakukan pemblenderan dan disaring untuk memperoleh luas permukaan yang besar.

\section{Ekstraksi Alginat}

Ekstraksi alginat yang dilakukan dengan menggunakan metode jalur asam alginat sesuai dengan penelitian Husni dkk. (2012). Metode ekstraksi yang dilakukan dengan cara bubuk rumput laut kering ditimbang sebanyak 100 gram kemudian direndam dengan $\mathrm{HCl}$ 1\% (1:30 b/v) dalam waktu 1 jam. Bubuk rumput laut dicuci bersih hingga $\mathrm{pH}$ netral dan selanjutnya dilakukan ekstraksi menggunakan $\mathrm{Na}_{2} \mathrm{CO}_{3} 2 \%$ dengan variasi 1:10, 1:20, 1:30, 1:40, 1:50 (w/v) pada temperatur $70^{\circ} \mathrm{C}$ dalam waktu 2 jam. Hasil ekstraksi disaring memakai vibrator 150 mesh dan menggunakan kain blacu dan pengaduk untuk mempermudahan penyaringan. Hasil filtrat kemudian ditambahkan $\mathrm{NaOCl}$ sebanyak $4 \%$ dari volume filtrat selama 30 menit. Selanjutanya ditambah $\mathrm{HCl} 10 \%$ hingga diperoleh $\mathrm{pH}$ 2,8-3,2 dan kemudian endapan yang terbentuk dipisahkan kemudian dicuci bersih. Hasil tersebut kemudian dikonversikan menjadi natrium alginat dengan melalui metode titrasi menggunakan larutan $\mathrm{Na}_{2} \mathrm{CO}_{3}$ $10 \%$ hingga mencapai $\mathrm{pH} 7$. Pemisahan filtrat natrium alginat dilakukan dengan menuang secara perlahan ke dalam isopropil alkohol (1:2, $\mathrm{v} / \mathrm{v})$ sambil diaduk dan didiamkan selama 30 menit. Natrium alginat dikeringkan sampai kadar air $\pm 12 \%$ menggunakan sinar matahari. Alginat yang sudah kering, digiling dengan blender untuk memperoleh bubuk natrium alginat.

\section{Analisis Data}

Parameter mutu hasil ekstraksi alginat yang diuji adalah rendemen (Subaryono, 2010), kadar air, kadar abu (AOAC, 1995), uji gugus fungsi (Silverstein, 1991), viskositas (Cottrel dan Kovacs, 1980) dan pengamatan warna (Hutching, 1999). Rancangan percobaan yang dipakai merupakan rancangan acak lengkap (RAL) berupa 5 perlakuan rasio $\mathrm{Na}_{2} \mathrm{CO}_{3}$ 1:10,1:20,1:30, 1:40, 1:50 (w/v) dan dianalisis dengan Analysis of Variants (ANOVA). Apabila hasil analisis menunjukkan beda nyata selanjutnya diuji lanjut dengan metode Duncan menggunakan tingkat kepercayaan 95\%.

\section{HASIL DAN PEMBAHASAN Rendemen}

Rendemen alginat diperoleh dari persentase hasil ekstraksi rumput laut berupa alginat kering dibagi bubuk rumput laut sebelumekstraksi.Hasil rendemen sebagaimana terdapat dalam Tabel 1 menunjukkan bahwa tidak ada pengaruh perbedaan penggunaan rasio $\mathrm{Na}_{2} \mathrm{CO}_{3}$ 1:10, 1:20, 1:30, 1:40, 1:50 (w/v) terhadap rendemen dengan kisaran 9,78 $\pm 4,14 \%$ sampai dengan $17,58 \pm 4,02 \%$.

Menurut Jayanudin dkk. (2014), rasio pelarut menjadi faktor yang mempengaruhi rendemen atau kadar natrium alginat. Semakin banyak jumlah pelarut maka alginat yang terekstrak juga semakin banyak dan akan memperbesar rendemen yang dihasilkan. Jumlah pelarut yang tinggi akan menurunkan tingkat kejenuhan pelarut sehingga alginat dalam dinding sel rumput laut dapat terekstraksi lebih baik. Penelitian ini menunjukkan bahwa tidak ada pengaruh perbedaan rasio pelarut terhadap rendemen, hal ini dapat disebabkan karena rendahnya kandungan manuronat/guluronat alginat. Kandungan manuronat/guluronat dalam alginat rumput laut cokelat berbeda-beda antara lain dipengaruhi oleh umur, spesies, dan habitatnya (Taylor, 1979). Omar dkk. (1988) melaporkan bahwa Sargassum sp. yang berusia tua memiliki rasio M/G sebesar 0,64 sedangkan yang berusia muda sebesar 1,27. Kandungan guluronat yang lebih banyak lebih mempengaruhi terhadap hasil. Habitat juga 
berpengaruh terhadap hasil alginat (Davis dkk., 2003; Mazumder dkk., (2016), sehingga diduga bahwa rumput laut cokelat $S$. muticum dari Alor, Nusa Tenggara Timur pada penelitian ini tergolong muda yang memiliki kadar manuronat yang tinggi, sehingga meskipun monomer guluronatnya banyak terendapkan, tidak berpengaruh signifikan terhadap mutu rendemen natrium alginat.

Table 1.

Pengaruh Rasio $\mathrm{Na}_{2} \mathrm{CO}_{3}$ terhadap Rendemen, Viskositas, Ph, Kadar Air, dan Kadar Abu Na-Alginat Sargassum Muticum

\begin{tabular}{l|l|l|c|l|l}
\hline Rasio $\mathrm{Na}_{2} \mathrm{CO}_{3}(\mathbf{w} / \mathbf{v})$ & Rendemen (\%) & Viskositas (cPs) & $\mathbf{p H}$ & Kadar air (\%) & Kadar abu (\%) \\
\hline $1: 10$ & $14,83 \pm 3,01^{\mathrm{a}}$ & $678,42 \pm 70,01^{\mathrm{a}}$ & $6,43 \pm 0,38^{\mathrm{a}}$ & $10,43 \pm 1,85^{\mathrm{a}}$ & $22,59 \pm 2,18^{\mathrm{a}}$ \\
\hline $1: 20$ & $17,58 \pm 4,02^{\mathrm{a}}$ & $443,07 \pm 8,13^{\mathrm{b}}$ & $7,00 \pm 0,82^{\mathrm{a}}$ & $11,59 \pm 0,26^{\mathrm{a}}$ & $26,49 \pm 2,90^{\mathrm{a}}$ \\
\hline $1: 30$ & $9,78 \pm 4,14^{\mathrm{a}}$ & $144,27 \pm 7,35^{\mathrm{c}}$ & $7,10 \pm 0,85^{\mathrm{a}}$ & $7,62 \pm 0,66^{\mathrm{a}}$ & $27,67 \pm 4,92^{\mathrm{a}}$ \\
\hline $1: 40$ & $14,74 \pm 1,61^{\mathrm{a}}$ & $43,33 \pm 20,82^{\mathrm{d}}$ & $7,30 \pm 0,72^{\mathrm{a}}$ & $10,59 \pm 1,34^{\mathrm{a}}$ & $28,65 \pm 6,43^{\mathrm{a}}$ \\
\hline $1: 50$ & $12,60 \pm 5,73^{\mathrm{a}}$ & $48,17 \pm 1,59^{\mathrm{d}}$ & $7,00 \pm 0,62^{\mathrm{a}}$ & $9,48 \pm 3,34^{\mathrm{a}}$ & $28,44 \pm 3,86^{\mathrm{a}}$ \\
\hline
\end{tabular}

Keterangan: Notasi yang berbeda pada kolom yang sama berarti terdapat beda nyata (Sumber: Nurkhanifah, 2018)

\section{Viskositas}

Viskositas merupakan parameter terpenting alginat yang menunjukkan kekentalan larutan (Aristiya dkk., 2017). Semakin besar kekentalan alginat maka kualitas semakin baik. Tabel 1 yang menunjukkan bahwa ratio 1:10 $\mathrm{w} / \mathrm{v}(678,42 \pm 70,01 \mathrm{cPs})$ berbeda nyata dengan rasio $1: 20 \mathrm{w} / \mathrm{v}(443,07 \pm 8,13 \mathrm{cPs})$, rasio $1: 30 \mathrm{w} / \mathrm{v}$ $(144,27 \pm 7,30 \mathrm{cPs})$, rasio $1: 40 \mathrm{w} / \mathrm{v}(43,33 \pm 20,82$ cPs) dan rasio $1: 50 \mathrm{w} / \mathrm{v}(48,17 \pm 1,59 \mathrm{cPs})$. Viskositas tertinggi pada penelitian ini terdapat pada rasio 1:10 sebesar $678,42 \pm 70,01 \mathrm{cPs}$. Hasil viskoitas ekstraksi alginat ini jika dibandingkan dengan standar telah memenuhi standar Industrial grade (Erningsih et al., 2014) dan food grade (Sinurat \& Marliani, 2017)

Banyaknya rasio $\mathrm{Na}_{2} \mathrm{CO}_{3}$ akan meningkatkan jumlah pelarut pada proses ekstraksi rumput laut cokelat dan akan mempengaruhi besar nilai viskositas natrium alginat (Jayanudin et al., 2014). Menurut McHugh (1987), rantai polimer, berat molekul dan hasil viskositas berbanding lurus. Semakin pendek rantai polimer natrium alginat, maka semakin kecil berat molekulnya yang menghasilkan viskositas yang rendah, sehingga pada penelitian ini sesuai dengan teori tersebut yang menunjukkan bahwa semakin tinggi rasio $\mathrm{Na}_{2} \mathrm{CO}_{3^{\prime}}$ semakin banyak pelarut yang dapat mengekstraksi rumput laut yang pada akhirnya akan memperbanyak rantai panjang alginat yang terpotong menjadi rantai pendek yang dapat menurunkan viskositas natrium alginat.
pH

Hasil pengamatan $\mathrm{pH}$ natrium alginat sebagaimana terdapat pada Tabel 1 menunjukkan bahwa $\mathrm{pH}$ pada rasio $\mathrm{Na}_{2} \mathrm{CO}_{3}$ $(1: 10,1: 20,1: 30,1: 40,1: 50) \mathrm{w} / \mathrm{v}$ adalah $6,43 \pm 0,38$ sampai $7,30 \pm 0,72$. Hasil $\mathrm{pH}$ tertinggi pada

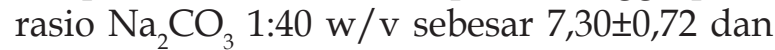
terendah pada rasio $\mathrm{Na}_{2} \mathrm{CO}_{3} 1: 10 \mathrm{w} / \mathrm{v}$ sebesar $6,43 \pm 0,38$. Hasil analisis menunjukkan bahwa tidak ada pengaruh nyata antara rasio pelarut dengan $\mathrm{pH}$ yang dihasilkan $(p=0,05)$ karena pada proses ekstraksi pada setiap rasio, nilai $\mathrm{pH}$ selalu dipertahankan sesuai dengan metode ekstraksi. Hasil ini jika dibandingkan dengan standar mutu $\mathrm{pH}$ natrium alginat FCC (1981) dan Aslan (1988) yaitu sebesar 3,5-10 pada industri pangan dan non pangan didapatkan telah sesuai dengan standar.

Hasil pH pada setiap rasio tergolong stabil karena menurut Bahar dkk. (2012), alginat stabil pada $\mathrm{pH}$ 5-10, sedangkan pada $\mathrm{pH}$ lebih tinggi dapat menyebabkan viskositas yang dihasilkan lebih kecil karena terdegradasi $\beta$-eliminatif. Susanto dkk. (2001) melaporkan bahwa semakin asam $\mathrm{pH}$ natrium alginat yang dihasilkan, maka akan bersifat lebih sensitif dan tidak stabil sehingga dapat menyebabkan depolimerisasi alginat dalam larutan. Menurut Wedlock dan Fasihuddin (1990), nilai pH yang mendekati netral dapat menyebabkan viskositas natrium alginat semakin tinggi, semakin tinggi $\mathrm{pH}$ menyebabkan semakin 
rendah viskositas yang didapatkan karena memiliki berat molekul yang rendah.

\section{Kadar air}

Pengujian kadar air dilakukan untuk menentukan kadar air yang terdapat dalam bubuk natrium alginat setelah dilakukan pengeringan. Tinggi rendahnya kadar air dalam ekstraksi dipengaruhi oleh proses pengenceran, penyaringan, dan pengeringan (Rasyid, 2003). Kandungan air juga dipengaruhi oleh jenis rumput laut dan kondisi habitatnya, serta selama proses ekstraksi pada tahap pemurnian, tahap pengeringan, serta tahap penyimpanan setelah penepungan (Mushollaeni dan Rusdiana, 2011). Tabel 1 dapat diketahui bahwa kadar air berkisar antara 7,62 $\pm 0,66 \%$ sampai $11,59 \pm 0,26 \%$ yang menunjukkan bahwa rasio pelarut tidak berpengaruh nyata terhadap kadar air natrium alginat S.muticum $(p=0,05)$, hal ini dapat terjadi karena pengaruh larutan yang digunakan saat dilakukannya pemurnian dan pengendapan natrium alginat yaitu isopropil alkohol pada setiap rasio pelarutnya sama sehingga tidak menimbulkan perbedaan kadar air selain itu metode pengeringan yang dilakukan yaitu menggunakan penjemuran sinar matahari hingga semua kadar air natrium alginat $<12 \%$. Hasil kadar air penelitian ini jika dibandingkan dengan standar mutu food grade oleh FCC (2003) telah memenuhi standar yaitu $\leq 15 \%$.

\section{Kadar abu}

Menurut Aristya dkk., (2017) abu adalah bahan tersisa hasil pembakaran yang merupakan zat-zat anorganik berupa mineral. Kadar abu dipengaruhi oleh proses pengeringan (Rasyid, 2003), jenis rumput laut cokelat dan habitatnya (Mushollaeni dan Rusdiana, 2011). Rumput laut yang mengambang dan tidak tersentuh dengan dasar pantai memiliki kadar abu yang lebih rendah. Rendahnya kadar abu dapat disebabkan oleh adanya sedikit residu yang tidak mudah terbakar seperti mineral dalam rumput laut (Mushollaeni dan Rusdiana, 2011).

Hasil kadar abu tertinggi terdapat pada rasio $\mathrm{Na}_{2} \mathrm{CO}_{3} 1: 40 \mathrm{w} / \mathrm{v}$ dan terendah 1:10 $\mathrm{w} / \mathrm{v}$ (Tabel 1) yang menunjukkan bahwa rasio pelarut tidak berpengaruh secara nyata terhadap kadar abu natrium alginat $(p=0,05)$, karena pemberian perlakuan pada rumput laut berupa perendaman dalam larutan $\mathrm{KOH}$ dengan konsentrasi yang sama setiap rasio pada persiapan awal rumput laut yaitu $0,1 \%$. Perendaman rumput laut dalam $\mathrm{KOH} \mathrm{0,1 \%}$ menghasilkan natrium alginat dengan kadar abu kadar abu rendah karena dapat mengurangi kadar mineral dalam natrium alginat yang dihasilkan (Darmawan dkk., 2006).

Hasil kadar abu dari hasil penelitian ini apabila dibandingkan dengan standar Food Chemical Codex (2003), pharmaceutical grade, standar indusri menunjukkan bahwa hasil memenuhi standar jika kisaran 18-27 \% maka rasio pelarut ekstraksi alginat $S$. muticum yang memenuhi standar kadar abu adalah rasio 1: 10 dan 1: 20 (w/v). Kadar abu penelitian ini tergolong tinggi hal ini diduga karena tahap praekstraksi mempengaruhi kadar abu. Kandungan mineral rumput laut cukup tingi, sehingga pencucian yang kurang bersih mempengaruhi mineral. Tinggi rendahnya kadar abu pada bahan dapat dihubungkan dengan unsur mineral dan jumlah mineral rumput laut tergantung spesies, faktor fisiologi, kondisi geografis, proses pengolahan yang diberikan. Menurut Erningsih et al. (2014), menambahkan bahwa kadar abu biasanya ditentukan oleh adanya halogen (Br dan I) dalam garam mineral.

\section{Derajat putih}

Derajat putih adalah merupakan parameter yang dapat menentukan tingkat warna putih dari suatu produk. Derajat putih diperoleh dari penggabungan nilai L*a*b. Nilai derajat putih dipengaruhi oleh agen pemucatan natrium alginat adalah $\mathrm{NaOCl}$. Pemucatan dengan $\mathrm{NaOCl}$ dapat memberikan warna kuning pucat pada natrium alginat (Omar dkk., 1988). Semakin banyak penggunaan bahan pemucat dapat menyebabkan terjadinya kerusakan kromofor sehingga kehilangan fungsinya dalam menyerap panjang gelombang warna yang menyebabkan peningkatan nilai derajat putih (Junaidi, 2006). $\mathrm{NaOCl}$ dapat menyebabkan teroksidasinya warna cokelat pada alginat. Senyawa fukosantin serta pigmen yang lain yang terdapat pada alginat dapat menentukan warna larutan (Finotelli dkk., 
2008). Menurut Junaidi (2006), pemakaian $\mathrm{NaOCl}$ sampai batas optimum dapat menyebabkan kromofor dalam ekstrak rumput laut cokelat semakin berkurang dan habis sehingga tidak terbawa dalam pembentukan natrium alginat. Oleh karena, itu derajat putih relatif meningkat sesuai dengan peningkatan konsentrasi bahan pemucatan sampai batas optimum. Selain itu warna cokelat juga dipengaruhi oleh jenis alginofit (Erningsih et al., 2014). Pada penelitian ini Nilai derajat putih WI (Whiteness index) yang diperoleh dari $L^{*} a^{*} b^{*}$ yaitu pada rasio $(1: 10 ; 1: 20 ; 1: 30 ; 1: 40 ; 1: 50) \mathrm{w} / \mathrm{v}$ adalah $38,85 \pm 1,24 ;$ $54,70 \pm 11,54 ; 56,22 \pm 6,39 ; 56,20 \pm 12,21 ; 50,09 \pm 5,65$ sehingga nilai tertinggi untuk derajat keputihan pada rasio $1: 30 \mathrm{w} / \mathrm{v}$ dan terendah pada $1: 10 . \mathrm{w} / \mathrm{v}$. Hasil analisis dapat diketahui bahwa tidak ada pengaruh nyata antara perbedaan rasio $\mathrm{Na}_{2} \mathrm{CO}_{3}$ dengan nilai derajat putih alginat (Tabel 2) karena pemberian $\mathrm{NaOCl}$ pada setiap rasio sama senilai $4 \%$ volume filtrat.

Tabel 2.

Hasil uji derajat putih Na-alginat

\begin{tabular}{|c|c|c|c|c|}
\hline \multirow{2}{*}{ Rasio $\mathrm{Na}_{2} \mathrm{CO}_{3}(\mathrm{w} / \mathrm{v})$} & \multicolumn{4}{|c|}{ Notasi Hunter } \\
\hline & $\mathbf{L}^{*}$ & $a^{*}$ & $\mathbf{b}^{*}$ & WI \\
\hline 1:10 & $39,55 \pm 1,13^{a}$ & $6,51 \pm 1,01^{\text {a }}$ & $6,41 \pm 1,48^{\mathrm{b}}$ & $38,85 \pm 1,24^{\text {a }}$ \\
\hline $1: 20$ & $57,26 \pm 12,80^{a}$ & $6,93 \pm 0,87^{a}$ & $12,18 \pm 3,48^{\mathrm{a}}$ & $54,70 \pm 11,54^{\mathrm{a}}$ \\
\hline $1: 30$ & $55,9 \pm 10,81^{\text {a }}$ & $7,72 \pm 1,31^{\text {a }}$ & $13,14 \pm 2,30^{a}$ & $56,22 \pm 6,39^{a}$ \\
\hline $1: 40$ & $58,83 \pm 12,85^{a}$ & $7,28 \pm 1,35^{a}$ & $12,61 \pm 0,74^{a}$ & $56,20 \pm 12,21^{\mathrm{a}}$ \\
\hline $1: 50$ & $52,61 \pm 5,67^{\text {a }}$ & $7,80 \pm 0,33^{a}$ & $13,10 \pm 1,24^{a}$ & $50,09 \pm 5,65^{\text {a }}$ \\
\hline
\end{tabular}

Keterangan:Nilai dengan notasi yang sama menunjukkan tidak terdapat beda nyata $(\mathrm{p}<0,05)$, WI: Whiteness index (derajat keputihan), L: Parameter kecerahan, a: (+) dari 0 hingga 100 untuk warna merah, (-) a dari 0 hingga -80 untuk warna hijau, b: (+) dari 0 hingga 70 untuk warna kuning, (-) dari 0 hingga -80 untuk warna biru.

Sumber: Nurkhanifah, 2018

\section{Gugus Fungsi Alginat}

Gugus fungsi alginat memperlihatkan puncak-puncak serapan yang diperoleh. Sinar infra merah jika dilewatkan melalui cuplikan senyawa organik maka dapat terjadi sejumlah frekuensi yang terserap, sedang Frekuensi yang lain akan diteruskan masing-masing senyawa hanya menyerap sinar infra merah pada frekuensi tertentu. Pola absorbansi yang terserap oleh tiap-tiap senyawa berbeda-beda, sehingga senyawa-senyawa dapat dibedakan dan ditentukan kuantitasnya (Sankari et al., 2010). Gugus fungsi yang dihasilkan dianalisa menggunakan spektrofotometer inframerah. Spektrofotometer inframerah dapat digunakan untuk mengetahui keberadaan ikatan kimia dalam senyawa organik. Hasil guus fungsi dapat dilihat pada Tabel 3. Menurut Bahar dkk. (2012) menyatakan bahwa gugus hidroksil (O$\mathrm{H})$ berada pada daerah serapan $3200-3500 \mathrm{~cm}^{-}$ ${ }^{1}$, COO-asimetris pada serapan 1600-1680 $\mathrm{cm}^{-1}$, karboksil (C-O) berada pada daerah serapan $1000-1300 \mathrm{~cm}^{-1}$. Ju et al. (2002) menyatakan COO- simetris pada daerah serapan 1410 $\mathrm{cm}^{-1}$ dan sidik jari guluronat pada $890-900 \mathrm{~cm}^{-}$ 1. Menurut Leal dkk. (2008) gugus fungsi CO streching uronic acid berada pada daerah serapan $948,98 \mathrm{~cm}^{-1}$.

Berdasarkan Tabel 3 dapat diketahui bahwa rasio $\mathrm{Na}_{2} \mathrm{CO}_{3}$ 1:10 dan 1:50 w/v tidak memiliki kandungan senyawa alginat. Pada rasio 1:10 w/v tidak memiliki CO stretching uronic acid dan gugus sidik jari guluronat karena rasio pelarut tersebut tidak melarutkan semua bubuk rumput laut sedangkan pada rasio $1: 50 \mathrm{w} / \mathrm{v}$ tidak memiliki CO stretching uronic acid dan sidik jari guluronat karena menurut Jayanudin dkk. (2014), penggunaan $\mathrm{Na}_{2} \mathrm{CO}_{3}$ yang besar akan meningkatkan ekstraksi rumput laut cokelat atau menarik alginat yang kemudian semakin banyak rantai panjang yang terpotong dan berakibatkan gugus fungsi tersebut tidak ada. Rasio (1:20, 1:30 dan 1:40) $\mathrm{w} / \mathrm{v}$ memiliki kandungan senyawa natrium alginat senyawa tersebut diantaranya adalah gugus hidroksil $(\mathrm{O}-\mathrm{H})$, $\mathrm{COO}-a$ asimetris, $\mathrm{COO}^{-}$ simetris, gugus karboksil (C-O), CO stretching uronic acid, dan sidik jari guluronat. 


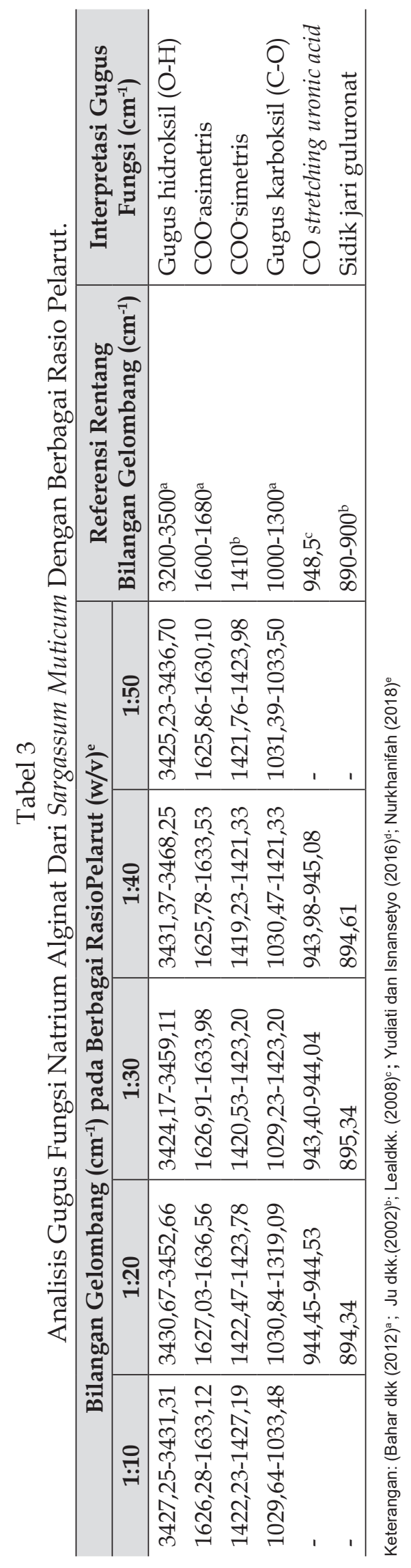

\section{SIMPULAN}

Rasio $\mathrm{Na}_{2} \mathrm{CO}_{3}$ berpengaruh terhadap mutu natrium alginat Sargassum muticum pada viskositas dan FTIR dalam ekstraksi menggunakan metode jalur asam. Rasio $\mathrm{Na}_{2} \mathrm{CO}_{3}$ terbaik pada mutu natrium alginat Sargassum muticum melalui ekstraksi jalur asam yaitu rasio 1:20 w/v. Rasio 1:20 w/v memiliki viskositas medium yang berbeda nyata dengan rasio pelarut lain, memiliki nilai $\mathrm{pH}$, kadar air, kadar abu sesuai dengan standar. Penelitian ini memiliki hasil derajat putih yang kurang baik, sehingga sebaiknya dilakukan penelitian lanjutan mengenai kadar $\mathrm{NaOCl}$ optimum untuk meningkatkan derajat putih pada Sargassum muticum.

\section{UCAPAN TERIMA KASIH}

Penulis menyampaikan banyak terima kasih kepada Direktorat Penelitian dan Pengabdian kepada Masyarakat Kementerian Riset, Teknologi dan Pendidikan Tinggi yang telah memberikan dukungan dana dari Skema Penelitian Strategis Nasional Institusi Tahun Anggaran 2018 dengan Perjanjian Penugasan Pelaksanaan Penelitian PSNI Nomor: 1754/ UN1/DITLIT/DIT-LIT/LT/2018.

\section{DAFTAR PUSTAKA}

Direktorat Jenderal Perikanan Budidaya. 2013. Volume Produksi KerapuRumput Laut-Nila 2009-2013. Jakarta: Data Statistik Perikanan.

AOAC. 1995. Official Method of Analysist of The Association of Official Analytical of Chemyst, USA: The Association of Official Analytical Chemyst, Inc.

Aslan, L. M. 1998. Budidaya Rumput Laut, Yogyakarta: Kanisius.

Aristya, I.M.T.W., Admadi, B. dan Arnata, I. W. 2017. Karakteristik Mutu dan Rendemen Alginat dari Ekstrak Rumput Laut Sargassum Sp. dengan Menggunakan Larutan Asam Asetat. Jurnal Rekayasa dan Manajemen Agroindustri, 5(1): 81-92.

Bahar, R., Arief, A. dan Sukriadi. 2012. Daya Hambat Ekstrak Na-alginat dari 
Alga Cokelat Jenis Sargassum sp. terhadap Proses Pematangan Buah Mangga dan Buah Jeruk Indonesia. Chimica Acta, 5(2): 22-31.

Cottrell, I. W., dan Konvacs, P. 1980. Alginates. Dalam R. L. Davidson (ed). Hand Book of Water-Soluble Gums and Resin. New York: McGraw-Hill Book Co.

Darmawan, M., Tazwir, dan Hak, N. 2006. Pengaruh Perendaman Rumput Laut Cokelat Segar dalam Berbagai Larutan terhadap Mutu Natrium Alginat. Buletin Teknologi Hasil Perikanan, 9(1):26-38.

Davis, T. A., Llanes, F., Volesky, B., dan Mucci, A. 2003. Metal Selectivity of Sargassum spp. and Their Alginates in Relation to Their a-L-Guluronic Acid Content and Conformation. Environmental Science and Technology, 37(2): 261-267.

Finotelli, P. V., Sampaio, D.A., Morales, M.A., Rossi, A.M., dan Rocha-Leao, M.H. 2008. Ca Alginate as Scaffold for Iron Oxide Nanoparticles Synthesis. Journal Chemical Enggineering, 25(4): 759-764.

Erningsih, R., Marlina, R., Mutia, T., Sana, A.W., dan Titis, A. 2014. Eksplorasi Kandungan Pigmen dan Alginat dari Rumput Laut Cokelat untuk Proses Pewarnaan Kain Sutera. Arena Tekstil, 20 (2): 73-80.

Food Chemical Codex. 1981. Comitte and Codex Specification, Washington: Nation Academy Press.

Food Chemical Codex. 2003. Sodium Alginate. Institute of Medicine (U.S). Committe on Food Chemical Codex, Washington: National Academies Press.

Husni, A., Subaryono, Y. Pranoto, Tazwir, dan Ustadi. 2012. Pengembangan Metode Ekstraksi Alginat Dari Rumput Laut Sargassum sp. sebagai Bahan Pengental. Agritech, 32 (1): 1-8.
Hutching, J.B. 1999. Food Color and Appearance. Edisi Kedua. Maryland: A Chapman and Hall Food Science Book, Gaithersburg.

Jayanudin., A.Z. Lestari, dan Nurbayanti, F. 2014. Pengaruh Suhu dan Rasio Pelarut Ekstraksi terhadap Rendemen dan Viskositas Natrium Alginat dari Rumput Laut Cokelat (Sargassum sp). Jurnal Integrasi Proses, 5(1):51-55.

Ju, H.K., Kim, S.Y., Kim, S.J., dan Lee, Y.M. 2002. PH/TemperatureResponsive Semi-IPN Hydrogels Composed of Alginate and Poly (N-Isopropylacrylamide). Journal of Applied Polymer Science, 83(3):11281139.

Junaidi, R.R. 2006. Kajian Penggunaan $\mathrm{NaOCl}$ dan Kaporit pada Pemucatan Natrium Alginat dari Rumput Laut Cokelat. Skripsi. Bogor: Fakultas Teknologi Pertanian Institut Pertanian Bogor.

Leal, D., Matsuhiro, B., Rossi, M., dan Caruso, F. 2008. FT-IR Spectra of Alginic Acid Block Franctions in Three Species of Brown Seaweeds.Carbohydrate Research, 343:308-316.

Mazumder, A., Holdt, S.L., dan Francisci, D.D. 2016. Extraction of Alginate from Sargassum muticum: Process Optimization and Study of Its Functional Activities. Journal of Applied Phycology, 28(6): 3625-3635

McHugh, D.J. 1987. Production, Properties and Uses of Alginate. In: D.J. McHugh (ed.) Production and Utilization of Products from Commercial Seaweeds, Rome: FAO of the United Nations.

Mushollaeni, W., dan Rusdiana, E. 2011. Karakterisasi Natrium Alginat Dari Sargassum sp., Turbinaria sp., dan Padina sp. Jurnal Teknologi dan Industri Pangan, 22(1): 26-32.

Nurkhanifah, S.I. 2018. Pengaruh Rasio Na2CO3 dalam Ekstraksi terhadap 
MutuNatrium Alginat dari Sargassum muticum (Yendo) Fensholt. Skripsi. Yogyakarta: Departemen Perikanan Fakults Pertanian Universitas Gadjah Mada.

Omar, S., Ahmad, N., dan Ahmad, F. 1988. Composition of Alginats from Brown Seaweeds, Sargassum and Padina spp. Journal of Pertanika, 11(1):79-85.

Rasyid, A. 2003. Alga Cokelat (Phaeophyta) sebagai Sumber Alginat. Oseana, 28(1): 33-38.

Rasyid, A. 2010. Ekstraksi Natrium Alginat dari Alga Cokelat Sargassum echinocarphum. Oseanologi dan Limnologi di Indonesia, 36(3): 393-400

Sa'adah, N. 2017.PengaruhMetodePresipitasi dalam Ekstraksi Terhadap Mutu Natrium Alginatdari Rumput Laut Cokelat (Sargassum muticum (Yendo) Fensholt, 1955). Skripsi. Yogyakarta: Departemen PerikananFakultas Pertanian Universitas Gadjah Mada.

Sankari, G., Krishnamoorty, E., Jayakumaran S., Gunasekaran, S., Priya, V.V., Subramaniam, S. dan Mohan, S.K. 2010. Analysis of Serum Immunoglobulins Using Fourier Transform Infrared Spectral Measurements. Journal Biology and Medicine, 2(2): 42-48.

Silverstein, R.M. 1991. Spectrometric Identification of Organic Compounds, New York: John Wiley and Sons Inc.

Sinurat, E., dan Marliani, R. 2017. Karakteristik Na-alginat dari Rumput Laut Cokelat Sargassum crassifolium Dengan Perbedaan Alat Penyaring. Jurnal Pengolahan Hasil Perikanan Indonesia, 20(2): 351-361.

Subaryono. 2010. Modifikasi Alginat dan Pemanfaatan Produknya. Squalen, 5(1): 1-7.
Sukma, I.W.A., Harsojuwono, B. A. dan Arnata, I.W. 2017. Pengaruh Suhu dan Lama Pemanasan Ekstraksi terhadap Rendemen dan Mutu Alginat dari Rumput Laut Hijau Sargassum sp. Jurnal Rekayasa dan Manajemen Agroindustri, 5(1): 71-80.

Susanto, T., Zailanie, K. dan Simon, B.W. 2001. Ekstraksi dan Pemurnian Alginat dariSargassum filinpendula Kajian dari Bagian Tanaman, Lama Ekstraksi dan Konsentrasi Isopropanol. Jurnal Teknologi Pertanian, 2(1): 10-27.

Taylor, W.R. 1979. Marine Algae of The Eastern Tropical and Subtropical Coasts of the Americas. The University of Michigan Press. America.

Wedlock, D. J., dan Fasihuddin., B. A. 1990. Effect of Formaldehyde Pretreatment on The Intrinsic Viscosity of Alginat From Various Brown Seaweeds. J. Food Hydrocol, 4(1):4147.

Wibowo, A., Ridlo, A. dan Sedjati, S. 2013. Pengaruh Suhu Ekstraksi terhadap Kualitas Alginat Rumput Laut Turbinaria sp. dari Pantai Krakal, Gunung Kidul-Yogyakarta. Journal of Marine. Research, 2(3):15-24.

Winarno, F.G. 1990. Teknologi Pengolahan Rumput Laut, Jakarta: Pustaka Sinar Harapan.

Yudiati, E. dan Isnansetyo, A. 2016. Characterizing the Three Different Alginate Type of Sargassum siliquosum. Ilmu Kelautan, 22(1):7-14.

Yulianto, 2007. Penelitian Isolasi Alginat Algae Cokelat dan Prospek Menuju Industri. Prosiding Seminar Riptek Kelautan Nasional, 104-108.

Zailanie, K., Susanto, T. dan Simon, B.W. 2001. Ekstraksi dan Pemurnian Alginat dari Sargassum filipendula Kajian dari Bagian Tanaman, Lama Ekstraksi dan Konsentrasi Isopropanol. Jurnal Teknologi Pertanian, 20(1): 10-27. 